\title{
Clube de História: experiências no estudo e na pesquisa da história e cultura afro-brasileira no Colégio Estadual Maria Isabel de Melo Góes, Catu-BA
}

\author{
History Club: Experiences in the Study \\ and Research of Afro-Brazilian History and Culture \\ at Maria Isabel de Melo Cóes State College, Catu-BA
}

Marcelo Souza Oliveira*

Delmaci Ribeiro de Jesus ${ }^{\star *}$

\section{RESUMO}

Esse texto traz um relato de experiências vivenciadas no processo de implantação e desenvolvimento das atividades do Clube de História e se debruça sobre a utilização do ensino por investigação como abordagem didática que foi utilizada para o cumprimento das Leis 10.639/03 e $11.645 / 08$, que instituem a obrigatoriedade do Ensino da História e da Cultura Afro-brasileira no Brasil. O Clube de História é um projeto de intervenção desenvolvido no Colégio Estadual Maria Isabel de Melo Góes na cidade de Catu-BA, constituído por estudantes do ensino médio, com o objetivo de investigar e popularizar os elementos que compõem a história e a cultura negra na cidade de Catu e regiões circunvizinhas.

Palavras-chave: ensino por investigação; história e cultura afro-brasileira; identidade

\section{ABSTRACT}

This text presents an account of experiences in the process of implementing and developing the activities of the History Club and focuses on the use of teaching by investigation as a didactic approach that was used to comply with Laws 10.639 / 03 and 11.645 / 08, which establish the obligation of Teaching Afro-Brazilian History and Culture in Brazil. The History Club is an intervention project developed at the State School Maria Isabel de Melo Góes in the city of Catu-BA, made up of high school students, aiming to investigate and popularize elements of history and culture in the city of Catu and surrounding regions.

Keywords: teaching by research; afrobrazilian history and culture; identity.

\footnotetext{
* Instituto Federal de Educação, Ciências e Tecnologia Baiano, Salvador, BA, Brasil. historiadormarcelo@hotmail.com

**Secretaria de Educação do Estado da Bahia, Salvador, BA, Brasil. delmaciribeiro@hotmail.com
} 
Esse texto traz um relato de experiências vivenciadas no processo de implantação e desenvolvimento das atividades do Clube de História $(\mathrm{CH})$ e se debruça sobre a utilização do ensino por investigação como abordagem didática que foi utilizada para o cumprimento das Leis 10.639/03 e 11.645/08, que instituem a obrigatoriedade do Ensino da História e da Cultura Afro-brasileira no Brasil. O CH é um projeto de intervenção desenvolvido no Colégio Estadual Maria Isabel de Melo Góes na cidade de Catu-BA ${ }^{1}$ que teve como objetivo investigar e popularizar os elementos que compõem a história e a cultura negra na cidade de Catu e regiões circunvizinhas. Constituído por estudantes do ensino médio, o grupo de pesquisa surgiu a partir de um problema relacionado a falta de políticas públicas e/ou projetos escolares que se atentem para a conservação de memórias sobre a cultura afro-brasileira no município. A partir da problematização "De que forma os estudantes negros/afrodescendentes, pertencentes à escola pública da cidade de Catu se percebem enquanto atores de transformação da realidade na qual estão inseridos?", o $\mathrm{CH}$ desenvolveu atividades investigativas, relacionadas à História do negro e seus descendentes em Catu e no Brasil.

O clube convida os estudantes da Escola Estadual Maria Isabel de Mello Góes para questionar a realidade na qual estão inseridos e, através da pesquisa, propor a (re)construção de conhecimentos de valorização das comunidades afrodescendentes que constituem o município de Catu e arredores. Esses estudantes vêm produzindo projetos de pesquisa exitosos, que são apresentados e premiados em Feiras de Iniciação Científica Júnior, corroborando com a qualificação do processo de ensino e aprendizagem da História da Cultura Afro-Brasileira, tendo como referência legal os parâmetros curriculares nacionais e as Leis 10.639/03 e 11.645/08 (BRASIL, 2013). Desta forma esse projeto se constitui inovador uma vez que utiliza das práticas da Educação Científica no estudo significativo de História, incomum como método no ensino de História na Rede de Educação do Estado da Bahia.

O texto está dividido em cinco partes: primeiramente fazemos uma discussão sobre algumas categorias que nos ajudam a compreender a experiência aqui analisada. Logo após apresentamos a metodologia de organização e execução do CH. Posteriormente, relatamos as experiências como docentes envolvidos e imbricados com a pesquisa histórica como princípio educativo. Por conseguinte, trazemos alguns relatos de estudantes que integraram o $\mathrm{CH}$ e que 
realizaram, sob a nossa orientação, pesquisas históricas em suas comunidades. Por último, pontuamos algumas contribuições dessas experiências para nossa prática para a Educação Histórica.

\section{CONSIDERAÇÕES TEÓRICO-MEOTODOLÓGICAS SOBRE O CH}

A origem do $\mathrm{CH}$ encontra-se na inquietação, no fazer pedagógico e se aproxima, enquanto referência, da própria escola que, em sua forma concreta, pode ser entendida como um objeto de análise e intervenção. Esse projeto de intervenção pode ser compreendido e desenvolvido como ação conjunta integrada por discentes e docentes, partilhada com o coletivo da escola. Trata-se de uma possibilidade de abordagem didática que, ao propor atividades investigativas, é capaz de potencializar a construção do conhecimento histórico e de identidades dos sujeitos que o integram em seus múltiplos espaços de convivência e ambientes educativos.

Trazer para a discussão aspectos teóricos que caracterizam a pesquisa como princípio educativo, a construção do conhecimento histórico e da identidade foram pressupostos teóricos que se fizeram necessários para a compreensão do processo ensino-aprendizagem que ocorrem nas atividades do clube. Nele os estudantes deixam o papel de ouvintes e passam a se posicionar enquanto pesquisadores, construtores de conhecimento, capazes de identificar problemas e buscar investigá-los, numa relação de diálogo com a realidade na qual fazem parte, uma oportunidade de transformação, que ultrapassa os limites da escola e se materializa numa educação que se evidencia como libertadora. Como afirma Paulo Freire em relação à criação de uma pedagogia crítica-educativa, desejamos uma "pedagogia que faça da opressão e de suas causas objeto de reflexão dos oprimidos, de que resultará o seu engajamento necessário na luta por sua libertação, em que esta pedagogia se fará e refará" (FREIRE, 2005, p. 34). Nesse prisma, a realização de pesquisas históricas com temática voltada às relações étnico-raciais, permitindo ao estudante observar em sua própria realidade questões e problemas ligados à sua comunidade, proporciona uma formação identitária e intelectual mais elaborada para a atuação enquanto cidadãos numa sociedade marcada por intensos processos de desigualdade raciais e sociais. 


\section{PESQUISANDO E APRENDENDO SOBRE TEMÁTICAS ÉTNICO-RACIAIS NA ESCOLA E NA COMUNIDADE}

Os temas de pesquisa que envolvem a História da cultura afro-brasileira trazem para o ambiente escolar o debate legitimado pelas leis 10.639/03 e $11.645 / 08$, mas que ainda não faz parte, em sua totalidade, das metodologias em exercício nas instituições de ensino no Brasil. A Lei 10.639/03, que instituiu o ensino de História e cultura da África e afro-brasileira como conteúdo obrigatório na educação básica, é resultado de lutas e movimentos sociais que reivindicam uma reparação histórica, para atenuar as mazelas que foram e continuam sendo praticadas contra a população negra que se estabeleceu no Brasil, desde o período Colonial.

Tendo como referência o cenário das escolas antes e depois da Lei $10.639 / 03$, fica evidente que, mesmo com a obrigatoriedade do ensino de História da África, isso não basta para tornar possível uma mudança de comportamento curricular que possibilite a inserção dos valores, da identidade e do reconhecimento da cultura afro-brasileira. No cotidiano das salas de aulas, a mera transposição didática não favorece a construção do conhecimento numa perspectiva crítica e dialógica. Nesse sentido, é de suma importância se repensar a metodologia do ensino de História, sobretudo da História da Cultura Afro-Brasileira.

O ensino da História da África não é uma tarefa fácil, pois existe uma imagem eurocêntrica que foi criada e recriada historicamente sobre a inferioridade do continente africano. Desse modo, entre a lei e a efetivação de currículos escolares que venham a integrar o eixo das discussões sobre a África, existe um caminho a ser percorrido. Pensar metodologias que sinalizem uma preocupação com a formação do cidadão e o desenvolvimento de uma consciência histórica são necessidades que estão para além de cumprir sistematicamente com o que está disposto na Lei 10.639/03. Com o objetivo de ampliar suas ações e torná-la mais efetiva, em março de 2008 foi publicada a Lei 11.645/08, que além da temática História e Cultura Afro-Brasileira, apresenta como obrigatório o ensino de História Indígena em todas as séries da educação básica.

Para além de conhecer as leis que instituem a obrigatoriedade do ensino de história da África no Brasil é preciso refletir porque elas foram criadas e qual o contexto em que se deu a proposição e aprovação dessas leis. Segundo 
Ki-Zerbo (2010), não é possível viver sem memória ou com a memória de outrem, a não ser que fosse feita uma escolha pela inconsciência e alienação. Ainda segundo o autor, esse retorno a si mesmo pode, aliás, revestir-se do valor de uma catarse libertadora, como acontece com o processo de submersão em si próprio efetivado pela psicanálise, que, ao revelar as bases dos entraves de nossa personalidade, desata de uma só vez os complexos que atrelam nossa consciência às raízes profundas do subconsciente.

Nesse contexto é imprescindível propor um ensino que possibilite ao educando entender o seu objeto de estudo e a si mesmo, numa perspectiva de libertação e (re)construção. Assim, a proposição de atividades investigativas relacionadas a projetos de pesquisa apresentou-se como possibilidade fecunda no processo formativo dos estudantes. Cabe destacar que esse tipo de abordagem ainda é pouco difundido no ensino de História na educação básica, sendo um pouco mais comum no campo do ensino das ciências naturais. Esse é um dos motivos que tornam o $\mathrm{CH}$ inovador, pois suas experiências demonstram a contribuição que a pesquisa, como princípio pedagógico, pode trazer não só para a Educação Histórica dos jovens estudantes no que tange às temáticas voltadas para as relações étnico-raciais, como também para a sua promoção, tanto na Escola quanto na comunidade, uma vez que o $\mathrm{CH}$ desenvolve também oficinas, palestras e apresentações onde tornam público os resultados de sua pesquisa. Registre-se que são pesquisas realizadas por estudantes afrodescendentes sobre sua comunidade cujos integrantes em grande parte compartilham da mesma identidade.

Compreender e discutir as relações étnico-raciais no contexto escolar é uma ação que requer situar-se no tempo e espaço, no qual desenvolve-se o alargamento das discriminações e, com a mesma intensidade, as proposições de naturalização do racismo. Estabelecer o ponto de partida para discutir as conformações sociais que camuflam as complexas relações étnicas existentes na sociedade, nos faz entender que a História orienta e auxilia os indivíduos na construção da identidade e colabora para sua ação prática na vida.

Lilia Schwarcz afirma que o racismo no Brasil situa-se na esfera da intimidade e na informalidade, ao mesmo tempo em que o mito da boa convivência se consolida na representação do que é ser brasileiro. Para a autora, as particularidades de nossa História no que diz respeito às relações étnico-raciais "fez da desigualdade uma etiqueta internalizada e da discriminação um espaço 
não formalizado" (SCHWARCZ, 1988, p. 184). Lamentavelmente, esse problema, muitas vezes, tem sido reproduzido nas escolas e mesmo nas aulas de História. Nesse sentido, segundo Santos,

a história narrada nas escolas é branca, a inteligência e a beleza mostradas pela mídia também o são. Os fatos são apresentados por todos na sociedade como se houvesse uma preponderância absoluta, uma supremacia definitiva dos brancos sobre os negros. Assim o que se mostra é que o lado bom da vida não é nem pode ser negro. Aliás, a palavra negro, além de designar o indivíduo deste grupo étnico-racial, pode significar sujo, lúgubre, funesto, sinistro, maldito, perverso, triste, nefando etc. (SANTOS, 2003, p. 27)

Reconhecer que as instituições de ensino são reprodutoras de verdades prontas e realidades descontextualizadas é o primeiro passo para buscar alternativas que possibilitem a inserção de uma política de valorização das raízes e ancestralidades que constituem o povo brasileiro em sua totalidade e não apenas a reprodução de um recorte branco, influente principalmente nas regiões Sul e Sudeste do Brasil. Aliado a esse problema, ainda existe a questão de que a História ensinada na maior parte dos municípios da região Nordeste tem como referência básica os manuais didáticos produzidos em sua maioria no Centro-Sul do Brasil, o que se constitui um problema já que alunos e professores não veem sua história representada, não possuindo, por vezes, identidade entre seu passado e o passado estudado nos livros didáticos. A identidade a qual nos referimos é cultural, onde os grupos étnicos se encontram e os indivíduos desenvolvem a sensação de pertença. Nesse contexto, o resgate da memória é de suma importância devido à construção de uma identidade que dialoga com o conceito de nação.

Dessa forma, ensinar e aprender sobre a cultura afro-brasileira no Nordeste do país, após 130 anos de uma abolição que se concretizou do ponto de vista legal, mas ainda apresenta importantes lacunas sociais, é perceber que, ao mesmo tempo, existe um movimento para esquecer e há também aqueles que se levantam contra o esquecimento, para que a memória continue sempre viva, em uma resistência para não silenciar seu passado e preservá-lo, visto que a memória é um elemento constituinte do sentimento de identidade, tanto individual como coletivo, além de ser, também, um fator extremamente impor- 
tante do sentimento de continuidade de coerência de uma pessoa de um grupo em sua reconstrução de si (POLLAK, 1989).

A memória histórica constitui um fator de identificação humana, é a marca ou o sinal de sua cultura. Reconhecemos nessa memória o que nos distingue e o que nos aproxima. Identificamos a História e os seus acontecimentos mais marcantes, desde os conflitos às iniciativas comuns. E a identidade cultural define o que cada grupo é, o que nos diferencia uns dos outros. Paul Thompson (1992) conclui que a memória é reconstrução elaborada a partir de parâmetros que são resultados da relação entre o homem e sociedade. A reconstrução do passado depende essencialmente da integração do indivíduo a um grupo social que compartilhe suas experiências e cuja existência dá sustentação à sua memória. Neste sentido, memória individual é, ao mesmo tempo, memória social. Entendemos, então, a importância revelada pelos estudantes de perceberem que estavam estudando sobre seus antepassados e que esses tiveram uma história que pôde ser pesquisada e até mesmo ensinada em sua escola.

Da mesma forma, as entrevistas com idosos, muitos desses seus parentes, por exemplo, levaram estudantes e professores a perceberem a riqueza cultural e as contribuições dos seus ascendentes para a construção da comunidade local. O CH, dessa maneira, tornou possível a valorização da memória e da identidade afrodescendente local. Essa relação nos fez refletir que a memória não é a busca de informações do passado para reconstitui-lo e, sim, um processo dinâmico da própria rememoração que vai sendo grafada, narrada, ou mesmo tornando-se fonte-histórica, utilizando da memória social que é um dos meios fundamentais de abordar os problemas do tempo e da História (LE GOFF, 1992).

A identidade cultural e a memória articulam-se, visto que a memória é um elemento essencial da identidade e contribui para a formação da cidadania, distinguindo os valores marcantes em relação a si própria e às outras culturas. O processo de construção de identidades está relacionado a um passado histórico com o qual a origem dessas identidades continua a manter uma relação de proximidade, um vínculo que mostra o quanto os recursos da História, da linguagem e da cultura são usados para a produção não daquilo que nós somos, mas daquilo no qual nos tornamos (HALL, 2000)

Através da memória e da construção da identidade de um grupo social, o $\mathrm{CH}$ se apresenta com a perspectiva de preservar a cultura e fazer dela cada vez 
mais presente no cotidiano dos estudantes, enquanto objeto de valorização, preservação e popularização. Desse modo, para ocorrer uma aprendizagem significativa, o educador precisa reconhecer e valorizar os conhecimentos prévios dos estudantes e suas diferentes relações identitárias, a partir da convivência e de contextos sociais que corroboram um processo educativo que favorece a inclusão social. É possível ponderar que estudar a História Local é uma possibilidade ímpar de refletir sobre problemas que afligem toda uma sociedade, indagar e conhecer as estruturas, possibilitando a compreensão de todo contexto social, político e econômico que não se encontram nos livros didáticos. Como afirma Goubert (1998, p.73), "a volta à História Local origina-se de um novo interesse pela História Social, ou seja, a História da sociedade como um todo".

O professor e o estudante como autores, a partir da investigação e análise das distintas fontes históricas, entendendo a sua cultura e o seu modo de vida, podem construir uma educação que possibilite a valorização e a compreensão das mais distintas realidades de forma contextualizada e prazerosa. Para Proença (1990, p. 99), "assiste-se presentemente ao desenvolvimento de uma História Local que visa tirar partido das novas metodologias e cujos temas poderão ter um aproveitamento didático motivador e estimulante".

Esse tipo de História pode ser compreendido também como estudo do meio, ou seja, "como recurso pedagógico privilegiado que possibilita aos estudantes adquirirem, progressivamente, o olhar indagador sobre o mundo de que fazem parte" (BRASIL, 2006). Desse modo, a pesquisa tem como função despertar no estudante um olhar crítico que possibilite discutir a sua realidade e perceber a cultura afro-brasileira enquanto um patrimônio a ser valorizado e preservado. Um olhar que não pode se adaptar à naturalização histórica da forma como vem sendo abordada a relação entre casa-grande e senzala, um olhar que deve ser de ruptura a partir de uma educação efetivamente capaz de transformar e libertar. Como afirma Paulo Freire,

a educação não pode ser instrumento de aprisionamento dos indivíduos, é necessário se buscar a autonomia, propor e acreditar que é possível haver mudanças, onde o saber da História deve ser entendido como uma possibilidade e não como determinação, incentivando não apenas constatar o que ocorre, mas também possibilitar a intervenção, fugindo de meras adaptações e se propondo a mudar e interagir com a realidade. (FREIRE, 2004, p. 24) 
Analisando essa perspectiva defendida por Paulo Freire, compreende-se que o papel do componente curricular "História" deve ser o de contribuir para a formação de uma consciência histórica, que na definição de Rüsen é uma categoria geral que não apenas tem relação com o aprendizado e o ensino da disciplina, mas cobre todas as formas de pensamento histórico; através dela se experiencia o passado e se interpreta como História (RÜSEN, 2010, p. ???). Ou seja, Rüsen entende a História tendo o papel de orientar, dar as condições para que os sujeitos se compreendam enquanto partícipes desse campo da ciência e possam assim orientar-se no tempo e construir conhecimento.

Conhecimento visto como diálogo entre conceitos e realidade social, como construção de significados e relações entre pessoas, ideias e objetos. Sob o prisma da Educação Histórica, a aprendizagem de História deve ser significativa aos sujeitos em termos pessoais, proporcionando a eles maior compreensão da vida humana. Desse modo, propor o ensino de História em uma perspectiva da construção de conhecimento sobre a cultura afro-brasileira não significa dizer que a História precisa ser ciência para ter valor social.

\section{O ENSINO POR INVESTIGAÇÃO E A EDUCAÇÃO HISTÓRICA DOS ESTUDANTES}

O método ao qual se associa a pesquisa realizada no $\mathrm{CH}$ tem como função estabelecer um caminho para os estudantes se referenciarem, porém não limita e não impossibilita a criação de novos roteiros e percursos. Contudo, se espera que, a partir da problematização da realidade na qual estão inseridos, os estudantes se reconheçam enquanto sujeitos de um contexto histórico e social que não pode ser ocultado nem silenciado por uma cultura eurocêntrica que insiste em descaracterizar os valores inerentes à cultura africana. Aprender a pesquisar, desenvolver um plano de pesquisa, definir problemas, justificar a importância do objeto de estudo, estabelecer uma metodologia, analisar resultados e praticar a seleção e a leitura das referências são habilidades a serem desenvolvidas no $\mathrm{CH}$, mas sem limitar o valor social da História à sua condição científica, linear e objetiva, tal como se espera das ciências naturais numa perspectiva positivista. $^{2}$

No processo de reflexão e discussões que ocorrem no $\mathrm{CH}$, fica posto para estudantes e professor a certeza de que o conhecimento é um processo e não 
um dado pronto, acabado, definitivo. A construção de conhecimento surge de um movimento de relações recíprocas entre o sujeito que conhece e o objeto a ser conhecido, inseridos em um contexto social e cultural no qual alunos, professor e conhecimento articulam diferentes vivências, interesses e expectativas. Divergindo das concepções mais tradicionais das ciências da natureza, que buscam as leis abrangentes para explicar fenômenos, a História se ocupa com o estudo das ações humanas no tempo. Entender como se constrói as pesquisas que resultam na História, possibilita a construção de conhecimento histórico, ainda que seja provisório e aberto a novas interpretações.

Pensar o ensino de História no século XXI é tarefa complexa, uma vez que em uma sociedade carregada de informações diversificadas, os indivíduos são confrontados com visões diferentes do mundo e, por vezes, conflitantes entre si, como também com os seus próprios conhecimentos. Na busca por uma reflexão sobre o passado e a conexão com um presente cada vez mais dinâmico é importante que

à realidade social em que o sujeito se move, enquanto fator relevante da aprendizagem, tem sugerido fortemente que a criança ou o jovem aprenderá melhor quando as tarefas que lhe são propostas fazem sentido em termos de vivência humana. (BARCA, 2000, p.???)

O ensino por investigação, tal como defende Anna Maria Pessoa de Carvalho, apresenta a ideia de que o processo de ensino e aprendizagem se inicia a partir de um problema. A autora afirma que

propor um problema para que os alunos possam resolvê-lo, vai ser o divisor de águas entre o ensino expositivo feito pelo professor e o ensino em que proporciona condições para que o aluno possa raciocinar e construir o seu conhecimento. No ensino expositivo toda a linha de raciocínio está com o professor, o aluno só a segue e procura entende-la, mas não é o agente do pensamento. (CARVALHO, 2013, p. 2)

A proposição do ensino por investigação objetiva uma busca por abordagens didáticas diferentes daquelas que têm sido mais comuns nos diferentes espaços educativos. Dentre as mais comuns, por exemplo, o professor fazendo anotações no quadro, seguidas de explicações, e os estudantes anotando e 
ouvindo-o dissertar sobre um determinado tópico de conteúdo. Uma expectativa que surge dessas ideias é a possibilidade de que o gosto pela aprendizagem e construção do conhecimento histórico seja nutrido entre os estudantes ao compreenderem que a História analisa as diferentes temporalidades e espaços como construções humanas, pautadas em crises, desafios, inquietações que podem trazer mudanças para nossas vidas.

Nesse contexto, o CH caracteriza-se por ser uma forma de trabalho cuja intenção é fazer com que a turma se engaje nas discussões, busquem a resolução de um problema, exercitem práticas e raciocínios de comparação, análise e reflexão. De acordo com Lúcia Helena Sasseron,

o ensino por investigação configura-se como uma abordagem didática, podendo, portanto, estar vinculado a qualquer recurso de ensino desde que o processo de investigação seja colocado em prática e realizado pelos alunos a partir e por meio das orientações do professor. Como abordagem didática, o ensino por investigação demanda que o professor coloque em prática habilidades que ajudem os estudantes a resolver problemas a eles apresentados, devendo interagir com seus colegas, com os materiais à disposição, com os conhecimentos já sistematizados e existentes. (SASSERON, 2015, p. 58)

Assim, o ensino por investigação caracteriza-se por ser uma atividade orientada pelo professor. Porém as interações ocorridas entre professor, alunos, materiais e informações é que de fato concretizam o processo de ensino por investigação. A atitude dos estudantes diante da proposição de não apenas serem observadores, mas principalmente se engajarem, possibilita o desenvolvimento de liberdade e autonomia intelectual, despertando nos indivíduos o desejo de efetivamente aprender. Uma aprendizagem e reflexão sobre conceitos a partir da identificação de problemas que estão postos, mas muitas vezes passam despercebidos, visto que se vivencia, em muitas escolas, a cultura burocrática da mera exposição de ideias que afasta o interesse dos estudantes.

Nessa perspectiva, não apenas conhecimentos curriculares podem ser trabalhados, e o CH estimula também o debate sobre questões morais e éticas relacionadas à cidadania e inserção dos estudantes enquanto sujeitos que integram a sociedade. Ao promover condições para que os alunos trabalhem ativa e conjuntamente na resolução de um problema, novas perguntas vão se construindo e possibilitando o estabelecimento de argumentação e debate de ideias. 
O ensino por investigação exige que o docente valorize e compreenda a importância de evidenciar as imprecisões dos estudantes, com o objetivo de se produzir reflexões a partir de "erros", conhecimentos prévios e a experiência que a turma traz das suas diferentes realidades. É um trabalho em parceria entre professor e estudantes. Uma construção de entendimento com os aspectos históricos estudados e sobre os conceitos, modelos e teorias que os compõem. Pode-se afirmar que é a construção de uma nova forma de vislumbrar os conhecimentos históricos e o modo como estamos a eles relacionados.

O processo de conhecimento histórico e sua adequação ao ensino-aprendizagem são aqui tratados a partir de uma proposta de trabalho que procura estabelecer o diálogo de uma pedagogia da inclusão - que visa à prática da cidadania e o respeito às diferenças - com a realidade da exclusão, que aponta justamente para a distância entre a teoria e a prática. Educar pela pesquisa e propor investigações que tornem possível a valorização da cultura negra é de fundamental importância para que a juventude, sobretudo, construa uma relação de pertencimento com a sociedade na qual está inserida. Apreender uma consciência histórica que possibilitará aos jovens dos bairros periféricos desbravarem a sua própria cultura e contextualizá-la no tempo vivido por eles, a partir da releitura de uma História que vem sendo silenciada e reduzida a estereótipos folclóricos.

Analisar e entender as relações entre senhores de engenho e os escravos e discutir a realidade dos bairros periférico da cidade é uma estratégia política para estimular os estudantes a se reconhecerem enquanto sujeitos de um espaço por eles vivenciados, nas periferias, nos distritos e nas escolas da rede pública de ensino de Catu.

\section{METODOLOGIA DE ORGANIZAÇÃO DO CH}

A implementação do clube no cotidiano das atividades do Colégio Estadual Maria Isabel de Melo Góes pode ser percebida a partir do método dialético, que considera que os fatos não podem ser analisados de forma descontextualizada dos aspectos social, cultural, político e econômico. Os estudantes que participam do $\mathrm{CH}$, a todo instante, são convidados a relacionar os fatos históricos mencionados no livro didático e nas fontes por eles analisadas com a História Local e com o cotidiano no qual estão inseridos. 
As etapas desenvolvidas para a implantação do $\mathrm{CH}$ ocorreram na seguinte ordem:

1. Reunião com a direção do colégio e lançamento da proposta de inserção do $\mathrm{CH}$ nas atividades dos estudantes que demonstrem desejo de participar;

2. Processo de seleção dos estudantes, através da divulgação da proposta do clube, entre os discentes do Ensino Médio;

3. Entrevista com os estudantes que desejem ingressar no clube;

4. Organização do cronograma de funcionamento do $\mathrm{CH}$;

5. Definição das reuniões do $\mathrm{CH}$, uma vez por semana, para a leitura, discussão e produção de textos sobre a História Local;

6. Orientação dos projetos de pesquisa dos estudantes, para submissão em Feiras de Ciências na cidade de Catu e realização de pesquisa de campo;

7. Realização de Oficina sobre História Local, em parceria com os professores, possibilitando aos estudantes do $\mathrm{CH}$, divulgarem suas pesquisas;

8. Compartilhamento de aprendizagens, na qual todos os envolvidos no projeto foram convidados a fazer o diagnóstico dos possíveis benefícios e/ou malefícios que a pesquisa e o conhecimento científico podem proporcionar ao ensino de História;

9. Análise da efetividade desse projeto de intervenção, enquanto estratégia pedagógica de ensino não formal de História, de práticas de iniciação científica na educação básica e enquanto instrumento de construção da cidadania do estudante.

Como alternativa para a dificuldade de se reunir com os estudantes foi criado um grupo em rede social para acompanhar as discussões, sugerir leituras e desenvolver ações que favoreçam a construção de projetos de pesquisa e, posteriormente, a apresentação em feiras de ciências. A periodicidade das discussões virtuais é semanal e os encontros presenciais quinzenalmente no turno oposto ao que os alunos estudam. Na tentativa de orientar e acompanhar todos os alunos foi preciso, em alguns momentos, fazer orientações até mesmo em períodos que extrapolam a carga horária de trabalho semanal do professor orientador. 
O roteiro de atividades do clube, no que diz respeito às reuniões com os estudantes, seguiu a sequência:

a) Apresentação da proposta, do projeto e estatuto do $\mathrm{CH}$;

b) Explicação sobre o diário de bordo, sua importância e necessidade de acompanhar o estudante durante sua estadia no $\mathrm{CH}$;

c) Brainstorming, com o objetivo de provocar os estudantes para pensar em possíveis temas de pesquisa que surgem a partir da observação dos problemas da realidade na qual estão inseridos;

d) Seleção de textos acadêmicos que possibilitem a reflexão sobre a cultura afro-brasileira e posterior escolha por parte dos estudantes de leituras que se sentem mais atraídos a fazer;

e) Realização, pelos estudantes, de fichamentos e anotações sobre as leituras e levantamento de pontos para discussão. Esses pontos são discutidos inicialmente em ambientes virtuais e depois é realizado um debate presencial. Nesse momento, existe o desenvolvimento da capacidade de ler, analisar, interpretar e se comunicar a partir de argumentos que buscam validar uma ideia;

f) Nos encontros seguintes os estudantes são apresentados à Plataforma Ápice Febrace (https://apice.febrace.org.br/Londe realizam o curso online "Metodologia da Pesquisa e Orientação de Projetos de Iniciação Científica", ofertado pelo site, que possibilita aprender mecanismos de pesquisa, conceitos de plano de pesquisa, diário de bordo e outros elementos fundamentais para o desenvolvimento de Iniciação Científica Júnior;

g) A partir da discussão e formação teórica, os estudantes são orientados na construção do plano de pesquisa e começam a pesquisar de fato, seguindo a metodologia definida no plano. Nessa etapa o professor orientador segue acompanhando o estudante em atividades de campo, onde são analisadas fontes e realiza-se o levantamento de dados;

h) Por fim, é feito o processamento dos dados obtidos, discutindo no grupo de trabalho, compartilhando ideias, fazendo registros no diário de bordo e fazendo reflexões sobre os objetivos que foram determinados e os resultados alcançados; 
i) As etapas registradas no diário de bordo são organizadas em um artigo, que é compartilhado com outros estudantes em oficinas, palestras e feiras de iniciação científica.

\section{RELATO DE EXPERIÊNCIAS SOBRE O CH}

Nessa seção, iremos descrever os aspectos que corroboraram para a consolidação da proposta do $\mathrm{CH}$. Iniciaremos pontuando as adversidades enfrentadas no decorrer das atividades vivenciadas no clube. Não tínhamos um espaço definido como nosso para realizar as reuniões, a cada reunião estávamos sempre em busca de um espaço. Esse aspecto físico trouxe consigo a ausência de computadores, impressoras e outros diferentes recursos que poderiam fazer das pesquisas propostas mais relevantes.

Outro entrave que merece registro refere-se ao contratempo para reunir os estudantes em um turno oposto ao do estudo regular o que retrata os embaraços de ser professor e pesquisador na rede pública estadual, uma vez que os horários das reuniões precisavam ser constantemente ajustados. Diante dos problemas surgiu a necessidade de buscar envolver mais estudantes e evitar a evasão. Desde o início da proposta do projeto de intervenção $\mathrm{CH}$, foi sendo observado de que forma o grupo de estudos, por mim descrito, podia envolver o maior número de estudantes num processo contínuo de aprendizagem e reflexões relativas à cultura afro-brasileira, mas que concomitantemente fomentasse o desenvolvimento de habilidades de leitura e escrita dos estudantes.

Fazendo uso do conceito de avaliação tendo como referência a definição abordada por Luckesi ${ }^{3}$, é possível observar uma evolução qualitativa no desempenho dos estudantes que estiveram participando ativamente do projeto de intervenção. No diagnóstico inicial que ocorreu nos primeiros encontros do $\mathrm{CH}$, em conversas com os estudantes, foi possível perceber o quanto estavam inseguros para falar, além de identificar um desinteresse pela leitura. No primeiro ano de realização do projeto, os estudantes tiveram dificuldades para identificar problemas e fazer reflexões a partir do objeto de estudo. Nesse contexto, participamos de duas feiras de iniciação científica: a Feira de Ciências das Escolas Estaduais de Catu e a Feira de Ciências e Empreendedorismo da Bahia. Nos dois eventos citados, no ano de 2016, a desenvoltura dos estudantes foi marcada por nervosismo e insegurança. Nesse período, percebemos a 
necessidade de se instituir uma cultura de pesquisa que até então não era prática comum, nem para os professores e nem para os estudantes do Colégio Estadual Isabel de Melo Góes. Era necessário, portanto, criar possibilidades para que, pouco a pouco, a cultura científica pudesse se inserir no cotidiano da Escola.

Ainda no ano de 2016, fizemos uma oficina na Escola Municipal Professor Raimundo Mata. O convite foi feito para discutir questões relacionadas à cultura afro-brasileira durante as festividades da Semana da Consciência Negra. $\mathrm{Na}$ oportunidade, os estudantes tiveram um desempenho satisfatório, estavam mais espontâneos e puderam trazer para a plateia de alunos do Ensino Fundamental II importantes reflexões sobre a Lei 10.639/03 no currículo das escolas da cidade de Catu, as questões relacionadas ao candomblé no espaço escolar, preconceitos, tabus e a beleza negra, com valorização da identidade e da cultura afro-brasileira no espaço escolar.

Nas conversas informais e/ou nos registros do diário de bordo, bem como nas apresentações durante as feiras, foi possível visualizar o quanto os estudantes se desenvolveram, no que diz respeito à articulação de ideias, a partir da leitura e escrita. No entanto, como já citamos anteriormente, desde 2016, o grande desafio foi envolver um maior número de estudantes. Mesmo tendo uma proposta que se diferencia do ensino formal, é significativo o percentual de abandono. Uma das razões é a disponibilidade dos discentes e docentes para enfrentar o currículo formal, encontrar tempo e espaço para pesquisar, desafios que estão longe de serem superados na rede pública estadual da Bahia.

No entanto, mesmo com os enfrentamentos, existia a necessidade de aumentar a quantidade de estudantes pesquisadores, pois a ideia de estudar a cultura afro-brasileira através da investigação protagonizada por estudantes da educação básica está diretamente relacionada com a ampliação da conscientização sobre a temática específica do projeto, enquanto uma ação afirmativa de valorização e empoderamento tanto dos estudantes do Colégio Estadual Maria Isabel de Melo Góes quanto da comunidade situada no seu entorno.

Como o projeto do $\mathrm{CH}$ não se insere no currículo regular da escola, um número reduzido de estudantes optava por participar do clube, o que limitava a sua atuação a um grupo de 10 estudantes. A escola, em sua imensa maioria, continuava à margem das discussões sobre a cultura afro-brasileira e não atendia às atribuições previstas nas Leis 10639/03 e 11645/08. 
Diante desse "problema" após 2 anos de atuação, o clube passou a proporcionar a sensibilização da comunidade escolar para a necessidade de propor a discussão contínua sobre a cultura afro-brasileira. O grupo de estudos influenciou diretamente a criação de um projeto interdisciplinar no Colégio Estadual Maria Isabel de Melo Góes: "Cultura afro-brasileira no espaço escolar: descolonizando narrativas e construindo saberes". Este possibilitou ampliar de forma contínua e mais ampla as discussões sobre a cultura afro-brasileira no espaço escolar, e envolve todos os estudantes da escola. O projeto iniciou as suas atividades no primeiro trimestre do ano letivo de 2018, com caráter interdisciplinar. Os estudantes foram envolvidos em oficinas de leitura, produção de textos, análise de documentários e participação em palestras. Os textos, documentários e palestras partiram de temas de um cenário local, a cidade de Catu e estimularam a reflexão e a produção sobre a cultura afro-brasileira.

Em 2016, quando surgiu o CH, a resistência dos estudantes no que diz respeito à compreensão de temas relacionados à cultura afro-brasileira era evidente. Após a dificuldade inicial, a participação e envolvimento dos estudantes revela o quanto ele contribuiu de forma significativa para estimular a conscientização sobre a cultura afro-brasileira. Partindo da ideia de respeito e humanidade, os estudantes conseguem se despir de preconceitos que estão presentes na família e em toda sociedade, estendendo-se para os demais espações sociais, incluindo a escola.

Os resultados foram relevantes, uma vez que além de prêmios obtidos em feiras de iniciação científica júnior, os estudantes do $\mathrm{CH}$ promoveram o início de uma reflexão necessária e contínua no espaço escolar. O combate à intolerância, a desmistificação da democracia racial, valorização da identidade e cultura afro-brasileira são elementos que passaram a fazer parte do projeto político e pedagógico da escola, não apenas o conteúdo que é superficialmente analisado no dia da "consciência negra".

\section{EXPERIÊNCIAS DOS JOVENS PESQUISADORES DO CH}

A dinâmica de ingresso e de atuação no $\mathrm{CH}$ tinha foco na promoção da autonomia e criatividade dos jovens pesquisadores. Eles tinham liberdade para observar e propor ideias de pesquisa. Sendo assim, todos os temas de pesquisa 
foram sugestões dos estudantes, inquietações que partiram da convivência desses indivíduos em suas comunidades, bairros periféricos e distritos da cidade de Catu, após identificar um problema da comunidade na qual está inserido. Seguindo essa dinâmica de trabalho, entre os anos 2016 e 2017 os estudantes que integraram o clube escolheram e desenvolveram os seguintes projetos: 1) “O Candomblé no Espaço Escolar, Preconceitos e Tabus"; 2) “A Lei 10.639 no currículo das escolas da cidade de Catu"; e 3) "Beleza Negra: valorização e identidade da cultura afro-brasileira, no espaço escolar".

A discussão da realidade vivenciada por estudantes da educação básica no seu cotidiano é o fator em comum dos projetos. Entender a realidade de preconceitos e discriminações e propor uma postura de enfrentamento dessas realidades, de forma crítica, é a possibilidade efetiva de despertar no estudante o interesse pela disciplina História, uma vez que se tem a noção dos significados e correlações do que se pretende discutir em sala de aula e suas relações com o cotidiano vivenciado por meninos e meninas negros(as) dos diferentes bairros periféricos e zona rural da cidade de Catu. Uma aprendizagem significativa que valoriza os conhecimentos prévios dos estudantes e que não ficará restrita à sala de aula, visto que os estudantes participam de exposições, oficinas e palestras em outras unidades de ensino, além de levar novos saberes para a sua comunidade, favorecendo o empoderamento e o fortalecimento da cidadania.

A questão identificada no projeto 1 provavelmente está presente em diversas escolas e em outros espaços sociais. Entender que existe um problema relacionado à intolerância religiosa, por si só já é relevante. Mas no momento em que o estudante tem uma motivação para debruçar-se sobre o tema com o intuito de aprender, construir conhecimento e buscar minimizar este problema na sua escola e, consequentemente, na sua comunidade, há um ganho imensurável.

Novas habilidades são desenvolvidas.Conversando com os professores das diferentes áreas do conhecimento, os mesmos trazem elogios para a melhora significativa apresentada pelos estudantes que participam do $\mathrm{CH}$. Não me refiro ao aumento quantitativo das notas, mas principalmente ao rendimento dos estudantes que passaram a ter melhor desenvoltura nas apresentações de seminários, além de elevar substancialmente as análises, a capacidade crítica e a interpretação.

O fato de entender o quanto é importante o processo de ensino e apren- 
dizagem, numa perspectiva de construção de conhecimentos e não simplesmente decorar para aferição em provas tradicionais, fez os estudantes terem uma relação de prazer com o ato de ler, deixando de ser uma obrigação cumprida na escola. Uma escola que dê força através de um sistema de notas, mensura quantitativamente o rendimento escolar de indivíduos cada vez mais robotizados, rotulados como desinteressados, mas que muitas vezes não conseguem construir conhecimento por não encontrar conexão entre os livros didáticos, a sala de aula e o seu cotidiano.

Para exemplificar esta situação, trago abaixo alguns relatos dos estudantes, coletados no próprio diário de bordo, uma vez que a cada etapa concluída no clube, eles são convidados a escrever sobre as aprendizagens e perspectivas, uma avaliação que busca ir ao encontro dos aspectos positivos que vem sendo conquistados através do projeto de intervenção, mas, sobretudo identificar o que precisa ser aperfeiçoado.

Sobre a participação no $\mathrm{CH}$ e o desenvolvimento de pesquisa relacionada com a intolerância religiosa uma das estudantes afirmou que

a importância de trabalharmos e discutirmos esse projeto fez com que olhássemos ao nosso redor e percebêssemos que o ambiente escolar precisa estar aberto para novas discussões, busca de mais conhecimento e é necessária a realização de projetos que fortaleçam ações afirmativas, como o $\mathrm{CH}$. Buscaremos aprofundar os estudos sobre a cultura afro-brasileira e ampliar a atuação do $\mathrm{CH}$, para além do Colégio Estadual Maria Isabel de Melo Góes. ${ }^{4}$

O projeto 2 - "A Lei 10.639 no currículo das escolas da cidade de Catu" - trouxe para os estudantes um amadurecimento político muito interessante. Durante as entrevistas, os discentes puderam constatar que a fala de professores, estudantes e secretárias de educação não caminhavam num mesmo sentido diante dos mesmos questionamentos, que tinham como objetivo entender de que forma a Lei 10.639/03 vem sendo aplicada na cidade de Catu. O exercício da entrevista e da análise das respectivas respostas fez com que os discentes se tornassem mais atentos no momento de ouvir notícias e interpretá-las como verdades ou mentiras. Quando questionados sobre os objetivos a serem alcançados com o projeto de pesquisa, um dos estudantes respondeu: 
A partir dessa pesquisa queremos sinalizar um problema, que é a falta de sensibilidade da comunidade escolar, para identificar no seu cotidiano situações que podem ser discutidas para termos uma educação que seja capaz de contribuir para uma sociedade cada vez melhor. Com base nos resultados iremos propor juntamente com a direção, professores e estudantes a ampliação do $\mathrm{CH}$ para desenvolver na escola projetos que possam contribuir para que tenhamos a valorização da identidade dos diferentes grupos étnicos que compõem a população brasileira. ${ }^{5}$

"Beleza Negra: valorização e identidade da cultura afro-brasileira no espaço escolar", foi o projeto 3. Na escola tem um grupo de meninas que adotam o cabelo crespo e outro grupo que recorre às técnicas estéticas para ter um cabelo "liso". Esse projeto trouxe para a discussão a necessidade da valorização da identidade e da cultura negra, inicialmente no espaço escolar. Ou seja, o que possivelmente já tinha um caráter natural para muitos estudantes, foi apresentado como um problema de pesquisa. Por que as meninas negras do Colégio Estadual Maria Isabel de Melo Góes têm como referência de beleza um padrão eurocêntrico? Esse questionamento resultou em um projeto de pesquisa e já é possível perceber que houve um aumento do número de meninas que adotaram seus cabelos cacheados e crespos, abandonando o padrão estético do cabelo liso. Na cidade de Catu surgiu um grupo de mulheres intitulado "empoderamento crespo" e o conhecimento inicialmente debatido no contexto escolar é percebido e vivenciado para além dos muros da escola.

Os projetos aqui mencionados iniciaram uma mudança de postura no Colégio Estadual Maria Isabel de Melo Góes. Em 2016 e 2017, as pesquisas dos estudantes foram compartilhadas na escola em reuniões e rodas de conversas, mas ainda faltava um envolvimento maior de estudantes e professores. Dessa forma, na jornada pedagógica de 2018 foi organizado o projeto "Cultura Afro-Brasileira no Espaço Escolar: descolonizando narrativas eurocêntricas e construindo saberes". A análise desse projeto interdisciplinar, enquanto desdobramento das ações do $\mathrm{CH}$, será analisada na próxima seção.

\section{O CH E SUAS CONTRIBUIÇÕES PARA A EDUCAÇÃO HISTÓRICA}

Ao longo do processo de desenvolvimento das ações do clube, foi possível verificar que é possível desmistificar a ideia presente entre os alunos de que estudar História é prender-se ao passado e, portanto, algo desnecessário. O 
envolvimento dos estudantes em suas pesquisas e a sensibilidade para observar problemas do seu cotidiano são extremamente significativos, visto que o protagonismo dos estudantes precisa ser cada vez mais estimulado.

Ao fomentar o ensino de História, num viés investigativo, os estudantes foram incentivados a pensar o problema como promotor de interações, individuais ou coletivas, e como indutor do processo de investigação no espaço escolar, um caminho que precisa ser percorrido por alunos e professores para que haja a construção de novos saberes que dialoguem com a realidade vivenciada.

Muitas vezes encarado como uma simples pergunta, o problema traz associado a si todo um contexto no qual a situação problematizada faz sentido, possibilitando que, em sala de aula, esta situação seja analisada. É preciso pontuar que um problema escolar é diferente de um problema científico. Na escola, o objetivo central é o contato dos estudantes com um conhecimento que a eles ainda não é conhecido, mas para o qual pode já haver certo consenso na comunidade científica. A resolução de um problema é um processo complexo que congrega ações de instâncias distintas desde aquelas mais ligadas a ações manipulativas, desenvolvimento e envolvimento cognitivo, até aspectos que demonstram uma construção teórica de conhecimento.

A ideia de investigação se relaciona com os processos por meio dos quais novos conhecimentos são construídos apoiando-se em resultados teóricos, dados empíricos, análise e confronto de perspectivas. Num processo aberto, desencadeado e dependente de características do próprio problema em análise, tendo forte relação com conhecimentos já existentes (aprendizagem significativa) e já reconhecidos pelos participantes do processo. Sob esta perspectiva, processos investigativos podem surgir como decorrência, desdobramento e continuidade de investigações em curso ou já realizadas. Desse modo, é importante a continuidade das atividades de pesquisa e investigação em busca de novos resultados que devem sempre ser confrontados.

Considerando a sala de aula, a abordagem precisa cuidar para que os conceitos e outros elementos da cultura científica não sejam apresentados como construções encerradas em si mesmas, não passíveis de questionamento. Desse modo, para Barca (2012) as pesquisas em Educação Histórica surgiram na tentativa de se ligar a teoria com a prática, isto é, não apresentar apenas propostas prescritivas não testadas em estudos empíricos, mas sim criar, implementar e analisar situações de aprendizagem reais, em contextos concretos, e disseminar resultados que possam ser ajustados a outros ambientes educativos. 
A possibilidade de desenvolver novas abordagens relacionadas ao ensino de História que aproximem o objeto de estudo da realidade ganha mais significado quando as experiências educativas podem ser adaptadas e replicadas em outros contextos educativos. Por isso, o ensino de História deve ter como fundamento o

desenvolvimento sustentado no conjunto de competências de interpretação e compreensão do passado que permite ler historicamente o mundo, a partir de crianças e jovens, dado que a aprendizagem se for explorada de forma desafiante, criativa e válida, apresenta fortes potencialidades como contributo para o desenvolvimento de competências cognitivas essenciais para a vida numa Sociedade da Informação e de Desenvolvimento. (BARCA, 2012, p. 37)

Pensar o ensino de História no século XXI é uma tarefa complexa, uma vez que em uma sociedade carregada de informações diversificadas, os indivíduos são confrontados com visões diferentes do mundo e que, por vezes, são conflitantes entre si e também com os seus próprios conhecimentos.

\section{CONSIDERAÇÕES FINAIS}

O CH tem alcançado seu objetivo, tanto é que foi considerado pela Secretaria de Educação da Bahia como um dos destaques no que tange aos projetos de intervenção desenvolvidos na rede pública do estado. Os estudantes que o integram, mesmo com as dificuldades, buscam fazer do $\mathrm{CH}$ um caminho para que a educação pública tenha uma melhor qualidade.

A proposta do clube de promover a pesquisa para discutir a valorização e o reconhecimento da cultura negra, nas suas diferentes representações, onde os estudantes são os protagonistas e sujeitos do processo de ensino e aprendizagem, tem sido realizada com êxito. Os problemas aqui relatados dificultaram as ações do projeto de intervenção, mas não foram obstáculos que impossibilitaram a sua realização.

Após o planejamento, a formação e consolidação do grupo de estudos, foi gratificante testemunhar que os estudantes membros do $\mathrm{CH}$ iniciaram uma inquietação de propor uma nova caminhada para o clube. $\mathrm{O}$ surgimento de um projeto interdisciplinar que tem perspectiva de integrar o projeto político pedagógico da escola é o legado que o $\mathrm{CH}$ deixa para o Maria Isabel de Melo 
Góes, além de evidenciar a capacidade e protagonismo dos estudantes, como elementos que precisam ser insistentemente relembrados e incentivados.

O grupo de pesquisa formado por estudantes da educação básica teve como principal enfrentamento a adequação ao currículo vigente. Participar de um grupo de estudos exige disciplina e comprometimento. É preciso ter sensibilidade para observar para além das necessidades curriculares que são impostas com "grades". Intervir no processo de ensino e aprendizagem é o caminho que se faz necessário para que tenhamos um cenário favorável nas escolas públicas. A valorização de estudantes e professores transforma um ambiente de caos em esperança de dias melhores.

O projeto de intervenção apresentou para o Maria Isabel de Melo Góes e para a comunidade situada em seu entorno o quanto é importante mobilizar os estudantes para que tenhamos uma escola que não se limite à transmissão de conteúdos que reforçam um discurso elitizado e homogeneizador, cerceando direitos e reproduzindo a voz do colonizador em contraposição ao silenciamento da nossa cultura afro-brasileira.

É possível avançar e replicar a ideia do $\mathrm{CH}$ em outros espaços educativos, Nesse sentido o projeto foi reconhecido e selecionado para ser divulgado para professores de todo o Brasil durante o evento Missão Pedagógica no Parlamento, no ano de $2017^{6}$, e o STEM TECH CAMP Brasil'. A Missão Pedagógica no Parlamento demonstrou interesse pelo projeto, pois compreendeu o quanto o $\mathrm{CH}$, ao conceber o estudante enquanto pesquisador, favorece a emancipação política e o exercício da cidadania, tendo como consequência o fortalecimento de uma educação para a democracia, mesmo num cenário político que não favorece o desenvolvimento de políticas educacionais democráticas. Por sua vez, o programa STEM TECH CAMP Brasil, que reuniu práticas pedagógicas inovadoras em Ciências, Engenharia e Matemática de todo o Brasil, trouxe para o $\mathrm{CH}$ o reconhecimento da sua aplicação nas áreas das ciências humanas, por provocar o estudante a estudar a partir de problemas, discutindo a realidade da sua comunidade e usando a pesquisa como um princípio educativo, num movimento coletivo capaz de transformar e libertar.

\section{REFERÊNCIAS}

BARBOSA, Joaquim Gonçalves; BATISTA MARTINS, João. Reflexões em torno da abordagem multirreferencial. São Carlos: Editora da UFSCar, 1998. 
BARCA, Isabel. O pensamento histórico dos jovens: idéias dos adolescentes acerca da provisoriedade da explicação histórica. Braga: CEEP/Universidade do Minho, 2000.

BARCA, Isabel. Ideias chaves para a Educação Histórica: uma busca de (inter)identidades. História Regional, Goiânia, v. 17, n. 1, p. 37-51, 2012.

BRASIL. Lei no 10.639 de 09 de janeiro de 2003. Diário Oficial da União, Brasília, 2003.

BRASIL. Lei 11.645/08 de 10 de Março de 2008. Diário Oficial da União, Poder Executivo, Brasília.

BRASIL. Parâmetros Curriculares Nacionais para o Ensino Médio: Ciências Humanas e suas tecnologias. Brasília: MEC, 2006.

CARVALHO, Anna Maria Pessoa de. Ensino e aprendizagem de ciências: referenciais teóricos e dados empíricos das sequências de ensino investigativas. In: LONGHINI, Marcos Daniel. O uno e o diverso na educação. Uberlândia: EdUFU, 2011.

CARVALHO, Anna Maria Pessoa de. O ensino de Ciências e a proposição de sequências de ensino investigativas. In: CARVALHO, Anna Maria Pessoa de (Org.). Ensino de Ciências por investigação: condições para implementação em sala de aula. São Paulo: Cengage Learning, 2013.

FREIRE, Paulo. Pedagogia da autonomia. 29. a ed. São Paulo: Paz e Terra, 2004.

FREIRE, Paulo. Pedagogia do oprimido. 42. ${ }^{\text {a }}$ ed. Rio de Janeiro: Paz e Terra, 2005.

GOUBERT, Pierre. História Local. Revista Arrabaldes. Rio de Janeiro, n. 1, 1988.

HALL, Stuart. Quem precisa da identidade? In: SILVA, Tomaz (Org.). Identidade e diferença: a perspectiva dos estudos culturais. Petrópolis: Vozes, 2000.

LE GOFF, J. História e Memória. Campinas: Unicamp, 1992.

LIBÂNEO, José Carlos. Didática. São Paulo: Cortez, 1991.

KI-ZERBO, Joseph. Introdução geral. In: KI-ZERBO, Joseph (Org.). História geral da África I: metodologia e pré- história da África. Brasília: UNESCO, 2010, p. XXXI-LVII.

POLLAK, Michael. Memória, esquecimento, silêncio. Revista Estudos Históricos, São Paulo: Cpdoc/FGV, v. 2, n. 3, p. 3-15, 1989.

PROENÇA, Maria Cândida. Ensinar/Aprender História. Lisboa: Horizonte, 1990.

RÜSEN, Jörn. Didática da História: Passado, Presente e Perspectivas a partir do caso alemão. In: BARCA, Isabel; MARTINS, Estevão de R.; SCHMIDT, Maria A. (Orgs). Jörn Rüsen e o ensino de História. Curitiba: Editora UFPR, 2010, p. 23-40.

SANTOS, Hélio. A busca de um caminho para o Brasil: a trilha do círculo vicioso. São Paulo: SENAC, 2003

SASSERON, Lúcia Helena. Alfabetización científica, enseñanza por investigación y 
argumentación: relaciones entre las ciencias de la naturaleza y la escuela. Ens. Pesqui. Educ. Ciênc. Belo Horizonte: UFMG, v.17, n. especial, p. 49-67, 2015.

SCHWARCZ, Lília Moritz. Nem Preto nem Branco, Muito pelo Contrário: cor e raça na intimidade. In: SCHWARCZ, Lília Moritz (Org.). História da Vida Privada no Brasil: contrastes da intimidade contemporânea. vol. 4. São Paulo: Companhia das Letras, 1998.

\section{NOTAS}

${ }^{1} \mathrm{O}$ município de Catu está situado a acerca de $78 \mathrm{~km}$ ao norte da capital baiana, na região metropolitana de Salvador.

${ }^{2} \mathrm{O}$ positivismo foi uma corrente de pensamento com ampla repercussão na Europa durante o século XIX e assentava-se na ideia de que a ciência é o nosso único meio de construção do conhecimento verdadeiro, ou seja, pregava uma espécie de primazia da ciência em detrimento de outras formas do conhecimento humano.

${ }^{3}$ Segundo o professor Cipriano Carlos Luckesi, citado por LIBÂNEO (1991, p. 196) "a avaliação é uma apreciação qualitativa sobre dados relevantes do processo de ensino e aprendizagem que auxilia o professor a tomar decisões sobre o seu trabalho".

${ }^{4}$ Depoimento de estudante que participa do $\mathrm{CH}$ e fez uma pesquisa sobre "O Candomblé no Espaço Escolar, Preconceitos e Tabus".

${ }^{5}$ Depoimento de estudante que participa do $\mathrm{CH}$ e fez uma pesquisa sobre "A Lei 10.639 no currículo das escolas da cidade de Catu”.

${ }^{6} \mathrm{O}$ programa Missão Pedagógica no Parlamento é uma formação para educadores que acreditam ser a escola um espaço importante para a formação democrática cidadã democrática, trabalhando temáticas como cidadania, política, democracia e poder legislativo em suas escolas. Disponível em https://escolavirtualdecidadania.camara.leg.br/site/850/missao-pedagogica-no-parlamento/. Acesso em 10 de agosto de 2018.

${ }^{7}$ O Programa STEM TechCamp BRASIL é uma iniciativa da Embaixada dos EUA no Brasil em parceria com o Laboratório de Sistemas Integráveis Tecnológico (LSI-TEC) e apoio da Escola Politécnica da Universidade de São Paulo (Poli-USP) e do Grupo +Unidos. Este programa tem como objetivo estruturar uma rede de multiplicadores formada por gestores das Secretarias Estaduais de Educação e professores líderes de ações escolares em Ciências, Tecnologia, Engenharias e Matemática (STEM), com potencial e liderança para articular e aprimorar ações existentes e elaborar e implantar novas ações voltadas à aprendizagem ativa de STEM nas redes públicas de educação básica do Brasil. Disponível em https://febrace.org.br/stemtechcampbrasil/. Acesso em 10 de agosto de 2018.

Artigo submetido em 14 de maio de 2020. Aprovado em 26 de julho de 2020. 